\title{
Axenfeld-Rieger syndrome
}

INSERM

\section{Source}

INSERM. (1999). Orphanet: an online rare disease and orphan drug data base. AxenfeldRieger syndrome. ORPHA:782

Axenfeld-Rieger syndrome (ARS) is a generic term used to designate overlapping genetic disorders, in which the major physical condition is anterior segment dysgenesis of the eye. Patients with ARS may also present with multiple variable congenital anomalies. 